\title{
What's the Rush? Tort Laws and Elective Early-Term Induction of Labor ${ }^{*}$
}

\author{
Louise Marie Roth \\ Associate Professor of Sociology \\ University of Arizona \\ 400 Social Sciences Building \\ Tucson, AZ, 85721 \\ lroth@email.arizona.edu
}

May 26, 2016

Journal of Health and Social Behavior 57(4): 486-501

doi:10.1177/0022146516669971

Approximate word count: 9,565

Tables: 4

Running Head: Tort Laws and Elective Early-Term Induction of Labor

\footnotetext{
* This material is based upon research supported by the National Science Foundation under grant 0958190. Any opinions, findings, and conclusions or recommendations expressed in this material are those of the author and do not necessarily reflect the views of the National Science Foundation. I wish to thank Terrence D. Hill for comments on an earlier draft and Megan M. Henley for excellent research assistance.
} 


\title{
What's the Rush? Tort Laws and Elective Early-Term Induction of Labor
}

\begin{abstract}
$\underline{\text { Abstract }}$
Tort laws aim to deter risky medical practices and increase accountability for harm. This research examines their effects on deterrence of a high-risk obstetric practice in the United States: elective early-term (37-38 weeks gestation) induction of labor. Using birth certificate data from the Natality Detail Files and state-level data from publicly available sources, this study analyzes the effects of tort laws on labor induction with multilevel models (MLM) of 665,491 early-term births nested in states. Results reveal that caps on damages are associated with significantly higher odds of early-term induction and Proportionate Liability (PL) is associated with significantly lower odds compared to Joint and Several Liability (JSL). The findings suggest that clinicians are more likely to engage in practices that defy professional guidelines in tort environments with lower legal burdens. I discuss the implications of the findings for patient safety and the deterrence of high-risk practices.
\end{abstract}




\section{What's the Rush? Tort Laws and Elective Early-Term Induction of Labor}

In American medicine, there is tension between organizational efficiency and quality of care (Hafferty and Light 1995; Szymczak and Bosk 2012). For example, clinical autonomy, a defining feature of the medical profession, can reinforce obsolete practices that undermine patient safety goals (Abbott 1988; Armstrong 2002; Friedson 1970; Timmermans and Kolker 2004). However, evidence-based medicine (EBM) places limits on physician autonomy by developing practice guidelines based on well-designed, clinically-relevant scientific research (Sackett 2000; Timmermans and Kolker 2004; Timmermans and Oh 2010). Many healthcare organizations adopted standardized protocols, practice guidelines, and outcome measures from EBM in the 1990s, when wide variation in clinical practices undermined claims that physicians uniformly offer the highest standard of care (Timmermans and Kolker 2004; Timmermans and Oh 2010).

Since the 1990s, sociological examinations of EBM have primarily focused on its effects on the medical profession's clinical autonomy, finding that the medical profession maintains control over clinical guidelines but they may reduce individual physicians' clinical autonomy (Mykhalovskiy and Weir 2004; Timmermans and Kolker 2004). Evidence-based guidelines aim to improve the quality and consistency of clinical decisions, although many physicians do not understand them, disregard them, or adapt them to fit their existing practice patterns (Armstrong 2002; Grilli and Lomas 1994; Grol 2001; Timmermans and Kolker 2004). This may lead to preventable adverse outcomes and malpractice liability, which is a major source of anxiety among physicians (Leigh et al. 2002). However, it is unclear how external legal regulations are related to adherence to EBM. Do providers respond to malpractice risk by engaging in more 
evidence-based practices that improve patient safety? Or does litigation risk inflate the costs of care without measurable impact on the quality of care?

Obstetrics is the specialty that faces the greatest risk of malpractice litigation. The obstetrics field also has a strong institutional bias toward active medical intervention, often in contradiction to scientific evidence (Davis-Floyd 2002; Simonds, Rothman, and Norman 2007). Consequently, this study examines the effects of tort laws on deterrence of a high-risk obstetric practice in the United States: elective early-term (37-38 weeks gestation) induction of labor. Obstetric guidelines recommend against elective induction before 39 weeks because of significant risks of neonatal mortality and morbidity (AHRQ 2009). Given known risks to patient safety, does liability risk deter elective early-term induction? This research analyzes the effects of state-level tort statutes on early-term induction of labor in mothers without a prior cesarean and without a clear medical need for early delivery. This departs significantly from most studies of medical malpractice, which focus on adverse events that have occurred and determine which ones were preventable and how many received compensation through the tort system (Brennan et al. 1991; James 2013; Leape et al. 1991; Localio et al. 1991; Studdert et al. 2005). Alternatively, I analyze the effects of tort laws on a practice that presents known risks of preventable adverse events, but does not produce bad outcomes every time. If fear of liability deters potentially injurious behavior, then reducing the risk of liability might embolden healthcare providers to take risks to patient safety. Combining individual-level data on births from the Natality Detail Files for 1995-2004 with state-level measures, I use multilevel models (MLM) to examine the effects of liability risk on the probability of labor induction in early-term births.

\section{EARLY-TERM INDUCTION}


Early-term induction rates have risen dramatically since 1990, far exceeding any increase in medical complications that necessitate early delivery (Murthy et al. 2011; Rayburn and Zhang 2002). While some deliveries before 39 weeks are medically necessary for maternal or fetal health, many early-term inductions are elective, meaning that labor is artificially stimulated for non-medical reasons. However, the evidence is clear: delivery before 39 weeks gestation poses significant short- and long-term risks to newborns (Clark et al. 2009; Engle and Kominiarek 2008; Spong et al. 2011). Recognizing this, the American College of Obstetricians and Gynecologists (ACOG) has defined a distinct "early-term" period from 37 weeks, 0 days, to 38 weeks, 6 days gestation, and explicitly recommends against elective early-term delivery because it poses unnecessary iatrogenic risks (risks induced by medical treatment or diagnostic procedures) (ACOG 2013b; Glantz 2005).

For infants, iatrogenic risks of early induction include a higher likelihood of respiratory distress, transient tachypnea (abnormally rapid breathing), ventilator use, pneumonia, respiratory failure, hypoxemia (an abnormally low concentration of oxygen in the blood), intraventricular hemorrhage (bleeding into the fluid-filled ventricles inside the brain), and hypoglycemia (low blood sugar) (Bates et al. 2010; Morrison, Rennie, and Milton 1995; Spong et al. 2011). Earlyterm newborns are more likely to be admitted to a neonatal intensive care unit (NICU) and to have 5-minute Apgar scores below 7. These adverse outcomes are more common in early-term births, regardless of whether medical risks are present before delivery.

For mothers, induction is associated with longer labor, greater risk of uterine hyperstimulation and non-reassuring fetal heart rate patterns, third and fourth degree perineal lacerations, increased blood loss, and pelvic floor injuries (Simpson and Thorman 2005). Labor induction substantially increases the probability of a cesarean delivery, which is associated with 
poorer maternal and child health outcomes (Ehrenthal, Jiang, and Strobino 2010; Signore 2010; Vrouenraets et al. 2005). Some negative infant outcomes from cesarean delivery are related to the lack of transmission of the mother's microbiome to the infant during vaginal birth (Dominguez-Bello et al. 2010; Gregory 2011).

Given that elective early-term induction of labor violates professional guidelines and carries known risks, why would providers engage in this practice? An important reason for the rise in elective inductions is mutual convenience for the patient and physician (Wing 2000). Pregnant women may request induction so that they can schedule their delivery around employment leave and the availability of support from family members, have their preferred physician attend the delivery, reduce their anxiety about knowing when labor will begin, or gain relief from physical discomfort at the end of pregnancy (Simpson 2010; Wing 2000). At the same time, patients cannot compel care providers to practice medicine in ways that serve their wishes - physicians and hospitals can refuse to offer procedures that are medically inappropriate or dangerous. However, physicians may offer or encourage procedures that pose some risk if they offer quality-of-life advantages. Labor induction gives physicians the ability to schedule deliveries on weekdays, during the day shift, or while on-call (Simpson 2010; Simpson and Thorman 2005; Szymczak and Bosk 2012). Payment structures encourage elective delivery because care providers often must attend the births of patients for whom they have provided prenatal care in order to receive their full reimbursement (Simpson 2010). Hospitals also gain efficiency from planning staffing schedules around inductions (Wing 2000). Thus, there are opposing institutional forces when it comes to elective early-term induction: patient safety and professional guidelines caution against it, but organizational efficiency and scheduling promote 
it. At the same time, willingness to take the risks associated with inducing labor before 39 weeks may be responsive to the tort environment, which is intended to deter high-risk behavior.

\section{THE LEGAL ENVIRONMENT}

Torts are the body of civil law that governs breaches of standards of care that individuals owe to one another as members of society, including duties of care from healthcare providers to their patients. Tort laws are a mechanism for making clinicians and hospitals accountable for unsafe or harmful practices in the American healthcare system, which has little regulation and few resources for assisting citizens with significant disabilities (Lofquist 2002). The tort system has three primary objectives: (1) to promote justice and redress violations of important norms, (2) to deter potentially harmful or injurious activities, and (3) to compensate victims for injuries caused by others' harmful activities (Abel 1987; Manzer 1987). This research focuses primarily on the second the goal: deterring potentially harmful practices.

While the medical liability system costs an estimated $\$ 55.6$ billion per year, or $2.4 \%$ of all health care spending, there are debates about whether malpractice suits are an effective deterrent against medical negligence (Mello et al. 2010). Those who view suits as an ineffective deterrent and an undue burden on care providers have lobbied for tort reforms. In the 1980s, insurers and corporations lobbied pro-business legislators to enact legislation that would cap damages and repeal common law protections for tort victims. By 1986, over 39 states had limited awards, and tort reform movements continued through the 1990s. Arguments for tort reform claim that malpractice suits inflate the costs of care and over-deter clinicians, leading to expensive over-treatment. While medical malpractice claims and the amount paid on these claims has been declining since the mid-1990s, reform advocates argue that liability concerns 
encourage clinicians to engage in defensive medicine, whereby they perform unnecessary tests and procedures in order to reduce the probability of lawsuits (Frakes 2012). Tort reform advocates also claim that many medical malpractice claims lack evidence of medical error or patient injury, and are thus frivolous (Lyon et al. 2007; Metzler and Meara 2012). Moreover, the tort system is inefficient for delivering justice, compensating victims, or deterring poor-quality care because most injured victims receive less than they deserve, and almost two dollars is spent in the tort system to deliver every dollar that an injured victim receives (Hyman and Silver 2006). However, tort reform arguments tend to focus primarily on the costs of the tort system and rarely address deterrence or quality issues. At best, they imply that the availability of legal remedies through the tort system is unnecessary to deter potentially harmful or injurious activities.

In contrast, most socio-legal scholars reject the rhetoric of over-deterrence and oppose tort reforms, especially caps on damage awards (Abel 1987; Hyman and Silver 2006; Mello and Brennan 2002). Population-based studies like the Harvard Malpractice Study (HMS) have found that approximately $1 \%$ of patients experience an injury due to negligence, estimating that between 44,000 and 440,000 people in the United States die from preventable medical errors each year (Brennan et al. 1991; Leape et al. 1991; Localio et al. 1991; Mello and Brennan 2002). Less than $1 \%$ of these injuries lead to payments, so providers are rarely accountable for substandard care (Abel 1987; Hyman and Silver 2006). Also, nearly all healthcare providers hold liability insurance that shields them from direct financial loss, and liability premiums are not responsive to individual clinicians' claims experience. Consequently, many scholars argue that the tort system under-deters medical negligence and under-compensates victims of negligent injuries (James 2013). 
What is the effect of tort laws on quality of care and adherence to EBM? Tort reforms that limit the cost of negligence could reduce caution on the part of providers, diminishing the deterrent effect of the tort system and reducing motivations to provide high quality care (Mello and Brennan 2002). For example, caps on damages reduce providers' legal risk by decreasing the cost of malpractice judgments associated with adverse medical events. Caps also apply regardless of whether clinicians and hospitals make any effort to improve care, so they do nothing to discourage risky medical practices (Avraham 2007; Currie and MacLeod 2008). Two types of caps on damages have become common since the 1980s: caps on punitive and noneconomic damage awards (Manzer 1987). Courts award non-economic damages to compensate for harms like permanent disability, disfigurement, blindness, loss of limb, paralysis, trauma, or physical pain and suffering. Non-economic damages are also called "compensatory" damages because they aim to compensate for the loss of quality-of-life for an individual and/or their family. These awards are often the only compensation that plaintiffs receive for the injury itself, in contrast to economic damages, which reimburse injured patients for out-of-pocket costs associated with medical bills, legal fees, or lost wages. In comparison, punitive damages are retributive rather than compensatory: these damages are intended to deter the defendant and others from engaging in similar conduct. Courts award punitive damages in only in $2 \%$ of civil cases that go to trial. The standard for punitive damages is higher than the standard for noneconomic damages because it requires that the clinician knowingly engaged in harmful action, but punitive and compensatory awards are strongly correlated (Eisenberg and Wells 2006).

Another important law is the Joint and Several Liability (JSL) rule, which is also called the "deep pockets rule" (MacCoun 1996; Vidmar 1997). JSL states that if two or more persons are liable in a case, they may be jointly and severally liable: claimants can pursue an obligation 
against any party that shares responsibility for a harm, even if that party is relatively blameless. Plaintiffs can then recover all of the damages from any defendant named in the suit, and the defendant with the most ability to pay (the "deepest pockets") can be liable for the full award if other defendants are unable to pay. JSL protects victims of negligence by ensuring that they receive compensation from some party involved in their injury, but it also means that large organizations make the majority of the payments to plaintiffs because of their ability to pay rather than their degree of responsibility. Many U.S. states have replaced JSL with Proportionate Liability (PL), whereby each co-defendant is liable in proportion to their direct responsibility. The available research on JSL reform suggests that a change from JSL to PL reduces malpractice suits and payments (Avraham 2007; Lee, Browne, and Schmit 1994). However, PL also makes care providers liable to the extent that they are responsible for harm and could increase their accountability, leading to more evidence-based practices. Some existing research has found that PL improves overall quality of care (Currie and MacLeod 2008).

Another important aspect of the legal environment surrounding maternity care is proximity to obstetric malpractice suits (Dranove and Watanabe 2009). Many physicians follow court rulings in malpractice cases and obstetric departments routinely discuss medical negligence rulings as well as adverse events and medical errors (Asher et al. 2013). Rates of malpractice suits and damage awards fluctuate, and more malpractice activity should increase awareness of legal risks and encourage more cautious practices. Very high payments in obstetric lawsuits should similarly increase the salience of legal risks. The impact of malpractice litigation may be cumulative, although recent activity appears to have a stronger effect than more distant events (Dranove and Watanabe 2009). 
In the United States, tort law has traditionally been a matter of state rather than federal law and tort statutes have evolved differently across states. Some states, including Texas, Georgia, and California, require the losing party to pay the court costs of the opposing party. Texas has implemented particularly aggressive tort reforms, creating \$600 million in savings for insurance companies during the 1990s. California, Indiana, and Michigan have very low caps on non-economic damages (maximum of \$250,000), although Michigan raises the cap for plaintiffs who are hemiplegic, paraplegic, or quadriplegic due to physician negligence. Five states have a single “Umbrella Limit" on total damages, ranging from \$250,000 (Indiana) to $\$ 2,500,000$ (Nebraska). Other states have implemented legislative changes to tort laws, only to have them later overturned by appellate courts as violating the state constitution. (For example, the Illinois legislature enacted caps on non-economic damages, but the state appellate court struck them down in Best v. Taylor Machine Works (1997) because a \$500,000 cap on damages invaded the power of the judiciary and made an arbitrary distinction between plaintiffs who sustained varying degrees of damages.) Because tort laws vary across states, examining induction in earlyterm births nested in states should illuminate the deterrent effect of tort laws.

\section{HYPOTHESES}

If fears about malpractice liability deter high-risk medical practices, then caps on damages that reduce liability risk should be associated with more early-term induction:

$\mathrm{H}_{1}$ : The odds of induction in early-term births will be higher in states with caps on damages than in states without caps.

Moreover, because punitive damages are less common than non-economic damages, caps on punitive damages will have smaller effects on legal risk. Caps on non-economic damages should 
also reduce legal risk in proportion to the size of the cap, with caps set at lower amounts having the weakest deterrent effect against risky medical practices. This leads to the following specific hypothesis:

$\mathrm{H}_{1 \mathrm{~A}}$ : The more that caps on damages reduce malpractice liability, the higher the odds of induction in early-term births.

The implications of reforming JSL are more complicated. On one hand, PL may reduce the number of lawsuits, which suggests the following hypothesis:

$\mathrm{H}_{2 \mathrm{~A}}$ : The odds of induction in early-term births will be higher in states with PL than in states with JSL.

However, PL can also make providers more accountable for the consequences of their actions, thus encouraging caution and adherence to evidence-based guidelines. This leads to the alternative hypothesis:

$\mathrm{H}_{2 \mathrm{~B}}$ : The odds of induction in early-term births will be lower in states with PL than in states with JSL.

Finally, proximity to legal activity should be associated with more cautious practices. Thus, I hypothesize that:

$\mathrm{H}_{3 \mathrm{~A}}$ : The odds of induction in early-term births will decline as the rate of obstetric malpractice lawsuits increases.

$\mathrm{H}_{3 в}$ : The odds of induction in early-term births will decline as the average payment in recent obstetric malpractice lawsuits increases.

I test these hypotheses using multilevel logistic models (MLM) of induction in early-term births nested in states from 1995-2004. 


\section{DATA AND METHODS}

To examine the effects of the legal environment on early-term induction without clear medical indications, I collected state-level measures from publicly available sources and combined them with 10 consecutive years of individual-level birth data from the Natality Detail Files (1995-2004). These years represent a period when the incidence of early-term induction was increasing and evidence that elective delivery before 39 weeks posed safety risks was mounting. The Natality Detail Files contain data on all recorded births in the United States (averaging slightly less than 4 million births per year). The year 2004 is the most recent year with information on the state of occurrence, so I could not match births with their state-level legal environment after 2004. Because of the large number of cases, I drew a 10\% random sample (nearly 400,000 per year).

The dependent variable is whether labor was induced in early-term (37-38 weeks gestation) births to mothers without a previous cesarean delivery (spontaneous early-term labor=reference). The analysis is limited to early-term births that involved labor and did not have clear medical indications for early delivery. Most women with a previous cesarean have a scheduled repeat cesarean without labor, which makes it inappropriate to examine labor induction in women with a previous cesarean. I selected out cases with multiple gestation (twins, triplets, etc.), a fetus in a breech position, or placenta previa (placenta attached over the cervix) because these cases usually involve a cesarean delivery without labor. I also selected out pregnancies with medical indications for early delivery: pre-eclampsia or eclampsia (pregnancyinduced hypertension that can lead to maternal seizures), low amniotic fluid (hydramnios/oligohydramnios), uterine bleeding, placental abruption (placenta separates prematurely from the uterus), or premature rupture of membranes. Thus, I analyze the odds of 
labor induction in births between 37-38 weeks gestation in mothers without a previous cesarean, with singleton, vertex pregnancies, and without clear clinical need for early delivery $(665,491$ births).

\section{$\underline{\text { Individual-level Measures }}$}

Variables in the dataset include place of delivery, person in attendance, parity, and medical and health data such as the number of prenatal visits, method of delivery, obstetrical procedures, medical risk factors, and infant health characteristics. Models include a continuous variable for the year of birth because there was a continuous increase in the early-term induction rate across this time period, rising from $13.25 \%$ in 1995 to $21.81 \%$ in 2004 . I also ran 3-level models with births nested in years and in states, treating year as a random effect. These models revealed that year explained only $1 \%$ of the variance and year-level random intercepts increased monotonically across this period, while other coefficients were the same (results are available from the author). Consequently, I present 2-level models of individuals nested within states, with a continuous variable for year, for greater ease of interpretation.

Demographic variables include the age, race-ethnicity, marital status, and education of the mother. I measure age and education in years. For race-ethnicity, I constructed mutually exclusive indicators for whether a mother identified as Hispanic/Latina, or non-Hispanic white (reference), Black, Native American, or Asian/Pacific Islander. Marital status is a dichotomous measure (married=1). Models control for parity (number of births) and the Adequacy of Prenatal Care Utilization (APNCU) index (1=inadequate, to 4=adequate+), which accounts for the month in which prenatal care began, the number of visits, and gestation length. The data contain no information about pre-pregnancy weight or body mass index (BMI) but gestational weight gain is an independent risk factor for complications and cesarean delivery, and excessive weight gain 
is most common among women who are overweight or obese before pregnancy (Getahun et al. 2007; Rosenberg et al. 2003). Consequently, models control for gestational weight gain of 45lbs or more, which exceeds the recommended upper limit for all pregnant women (401bs for underweight women and 20lbs for obese women) (Institute of Medicine 2009). Women who have previously given birth to a large baby $(>4 \mathrm{~kg})$ or have pregnancy-related risks such as diabetes and chronic hypertension are at elevated medical risk for early delivery, although these conditions are not absolute indications. As a result, models control for these risk factors to better isolate the effects of state-level variables, independent of clinical factors. I used multiple regression to multiply impute missing values for maternal education (1.2\% missing), APNCU (9.2\%), or weight gain $(17.7 \%)$ based on available maternal and pregnancy-related characteristics. I used listwise deletion for cases that were missing on induction $(0.4 \%)$, weeks of gestation $(1.1 \%)$, parity $(0.3 \%)$, hypertension $(0.5 \%)$, or diabetes $(0.05 \%)$.

\section{$\underline{\text { State-level Measures }}$}

While the primary state-level variables of interest are tort laws, a variety of state-level influences may drive some variation in the odds of early-term induction, such as socioeconomic status, female labor force participation (FLFP), and the healthcare system. Consequently, I control for per capita income, adjusted for inflation in 2004 dollars (http://www.bls.gov/data/inflation_calculator.htm), percent of the population living below the federal poverty line, and FLFP rate. I control for percent enrolled in health maintenance organizations (HMOs) or Medicaid programs, percent uninsured, and number of hospital beds per 1,000 population to account for the healthcare environment.

To measure malpractice litigation activity, I used the National Practitioner Data Bank (NPDB) Public Use Data File, which contains data on 12,029 obstetrics-related suits involving 
acts committed between Jan. 1, 1994 and Dec. 31, 2004. I used vital statistics on the number of births by state to calculate the rate of obstetrics-related malpractice suits per 100,000 births in the previous year. The NPDB also contains information on payments, and I calculated the average payment for obstetrics suits that settled in the previous year, adjusted for inflation in 2004 dollars. (Using the rate of suits or average payments for the previous year and the current year combined, or the current year alone, produced similar results.) Suits are usually settled in different years from the occurrence of the adverse event, so these suits do not directly correspond to each other. While more detailed data by month and zip code would better gauge providers' responses to local cases, they were not available.

I used public sources to obtain tort laws over time, including caps on damages and JSL versus PL. Following Yang et al. (2009), I code caps on damages as four dummy variables ranked from smallest to largest reduction in liability risk: punitive damages only, caps on noneconomic damages set higher than $\$ 500,000$, caps on non-economic damages between $\$ 250,001$ and $\$ 500,000$, and caps of $\$ 250,000$ or less. The reference category is no caps on damages. Reform of the JSL is coded dichotomously, with 0 representing JSL, and 1 representing PL or the requirement that an actor be responsible for at least $20 \%$ of the harm to be liable. I measure tort laws by state-month, so that individual births are nested within a legal environment that can change as legislatures pass or repeal tort reforms. (Appendix Table A summarizes state-level tort laws and their changes over time.)

\section{$\underline{\text { Statistical Model }}$}

I constructed multilevel logit models to analyze the effects of the tort environment on the odds of labor induction in births between 37 weeks, 0 days and 38 weeks, 6 days gestation. Multilevel modeling (MLM) provides unbiased estimates of state-level effects by accounting for 
the non-random nature of state-level error terms (Raudenbush and Bryk 2002). Like a fixed effects model, MLM uses clustered data and is designed to handle heterogeneity across contexts. Fixed effects models control for differences across states, while MLM analyzes both levels (individuals and states) to account for the effects of state context (Allison 2009; Ene et al. 2015; Raudenbusch and Byrk 2002). As a robustness check, I ran logistic regression models with fixed effects for states and the results were essentially the same (results available from the author).

This analysis uses two nested levels, assessing the effects of the legal environment on births that are nested within states. At the individual-level are the dependent variable measuring whether early-term labor is spontaneous $(=0)$ or induced $(=1)$, and measures of maternal and pregnancy characteristics from the Natality Detail Files. At the state-level, models include economic and healthcare controls, tort statutes, and litigation activity. This leads to the following prediction equation:

$$
\begin{aligned}
& \log \left[\frac{\text { induction }}{(1-\text { induction })}\right] \\
& =\gamma_{0}+\gamma_{1}\left(\text { maternal and pregnancy characteristics }{ }_{i j}\right) \\
& +\gamma_{2}\left(\text { state economic and health care environment } \text { en }_{j}\right) \\
& +\gamma_{3}\left(\text { state tort laws } s_{j}\right)+u_{0 j}+e_{i j}
\end{aligned}
$$

In this equation, $\gamma_{0}$ is the individual-level intercept, $\gamma_{1}-\gamma_{3}$ are the vectors of fixed-effect coefficients for individual- and state-level variables, $i$ represents the individual case, $j$ represents the state in which the birth occurred, $u$ represents the random (state-level) intercept, and $e$ is the error term. The models account for clustering within states and compute maximum-likelihood standard errors for clustered data. While the slope or magnitude of individual-level variables can vary across states, the best fitting model is an intercept-only model that treats the direction and magnitude of the fixed effects as similar across states. I used the PROC GLIMMIX procedure in 
SAS to estimate multilevel logit models with true maximum likelihood estimates (not approximations) (Ene et al. 2015).

\section{RESULTS}

$\underline{\text { Descriptive Statistics }}$

Table 1 describes the state-level control variables. During this period, average per capita income was $\$ 31,480$ in 2004 dollars, $12.15 \%$ of the population lived in poverty, and $62 \%$ of women were in the labor force. In terms of health insurance, $20.25 \%$ were enrolled in HMOs, $14.05 \%$ were uninsured, and $11.17 \%$ were on Medicaid plans. States averaged 3.25 hospital beds per 1,000 population. The average rate of obstetric malpractice suits was 28 per 100,000 births and cases that settled during this period awarded an average of $\$ 435,435$ in 2004 dollars.

[Table 1 about here]

Table 2 illustrates tort measures for 1995-2004. Over one fifth of state-months (21.9\%) during this period had caps on punitive damages only, while $13.8 \%$ had caps on non-economic damages over $\$ 500,000,15.5 \%$ had caps of $\$ 250,001-\$ 500,000$, and $9 \%$ had caps at or below $\$ 250,000$. States had PL or a requirement that defendants be responsible for at least one fifth of the damages in $57.3 \%$ percent of state-months.

[Table 2 about here]

Table 3 compares descriptive statistics for spontaneous (82\%) and induced (18\%) earlyterm births. The mothers in the sample averaged 27 years old and 12.8 years of education. Twothirds (66\%) were married when they gave birth. In terms of race-ethnicity, $21 \%$ identified as Hispanic, $77 \%$ were non-Hispanic white, $16 \%$ were non-Hispanic Black, $5 \%$ were Asian, and $1 \%$ were Native American. On average, mothers were having their second births and the 
APNCU score was 3.1, which represents adequate care. Mothers with early deliveries gained an average of 29.9 pounds during their pregnancies, $0.8 \%$ had previously given birth to an infant weighing more than $4 \mathrm{~kg}, 3 \%$ had diabetes, and $0.9 \%$ had hypertension. Table 3 reveals significant differences between mothers with spontaneous and induced early-term labor. As expected, inductions were more common in women that gained more than 45 pounds, had a previous large infant, or had diabetes or hypertension. Controlling for these risks in the models isolates the effects of non-medical variables like maternal demographic characteristics, statelevel characteristics, and tort laws.

\section{[Table 3 about here]}

\section{Explanatory Models}

Table 4 presents three multilevel logit models of births nested in states. One expects some state-level variation in practices like early-term induction because many statistical reporting practices, public health policies, insurance plans, and liability insurance premiums vary at the state level. The intraclass coefficient (ICC), which measures the proportion of variance that is between states, is 0.0275 , suggesting that $2.75 \%$ of the variance in the odds of induction occurs between states (Raudenbush and Byrk 2002). This ICC suggests that individual characteristics are the primary source of variation in early-term induction.

\section{[Table 4 about here]}

Model 1 examines the effects of individual demographic and pregnancy characteristics only, while controlling for clustering of cases within states. This model reveals that the odds of induction increased an average of $7 \%$ per year. There was a very small but significant decline in the odds of induction with each additional year of maternal age ( $2 \%$ for every 5 years). The odds of induction increase by $4 \%$ with each additional year of education, and married women have $9 \%$ 
higher odds of early-term induction than unmarried women. The odds also vary by raceethnicity, and are $42 \%$ lower for Hispanic mothers, $38 \%$ lower for non-Hispanic Black mothers, 23\% lower for Native American mothers, and 49\% lower for Asian mothers than for nonHispanic white women. This suggests that early-term induction is more common in non-Hispanic white women, married women, and women with more education.

According to Model 1, the odds of early-term induction are 7\% higher with each additional birth and increase at higher levels of the APNCU index. Weight gain of over 45 pounds increases the odds of induction by $26 \%$. Women with a previous high-birth-weight infant are 2.48 times more likely to have an early-term induction than a spontaneous early-term birth, while diabetes and chronic hypertension increase the odds of induction by factors of 2.29 and 3.79 respectively.

Model 2 adds state-level controls, which have very small effects. A likelihood-ratio test (LR test) comparing nested models reveals that Model 2 significantly improves upon Model 1 ( $<<0.0001)$, although state-level controls have very small effects. ${ }^{1}$ Unobserved heterogeneity can vary across models and bias the predicted probabilities based on logit coefficients, although the individual-level variables are fixed across the three models (Allison 1999; Mood 2010). To guard against problems with unobserved heterogeneity when adding tort variables to Model 3, I also ran linear probability models as a robustness check and compared the coefficients across models, finding that the statistical significance and direction of the coefficients did not change from Model 1 to Model 2 or from Model 2 to Model 3 (Mood 2010). In Model 2, the odds of earlyterm induction are lower in states with higher per capita income and/or with a larger percent of the population insured by Medicaid, and higher in states with more of the population enrolled in HMOs. A higher ratio of hospital beds per 1,000 population is associated with lower odds of 
early-term induction, possibly due to reduced scheduling pressures and greater organizational capacity to manage the flow of patients when there are more beds.

Model 3 adds the effects of the state-level tort environment and tort laws have significant and substantial effects. A LR test and a comparison of the AIC/BIC for Models 2 and 3 reveals that Model 3 significantly improves upon Model 2 ( $\mathrm{p}<0.0001)$. As predicted in $\mathrm{H}_{1}$, caps on damages are associated with higher odds of early-term induction. Caps on punitive damages alone increase the odds of induced rather than spontaneous labor by $15 \%$ over no caps, while caps on non-economic damages of over $\$ 500,000, \$ 250,001-\$ 500,000$, and $\$ 250,000$ or less are associated with $34 \%, 30 \%$, and $39 \%$ higher odds respectively compared to no caps. This provides support for $\mathrm{H}_{1 \mathrm{~A}}$, suggesting that practitioners are more willing to induce early labor for marginal medical reasons when state laws limit their legal risk. In terms of JSL reform, PL is associated with $22 \%$ lower odds of induction of early-term labor compared to JSL. Thus, rather than reducing the deterrent effect of the tort system by suppressing malpractice lawsuits $\left(\mathrm{H}_{2 \mathrm{~A}}\right)$, PL appears to encourage clinicians to practice more evidence-based medicine (supporting $\mathrm{H}_{2 \mathrm{~B}}$ ).

State-level obstetric malpractice activity has no noteworthy effects, failing to support hypotheses $\mathrm{H}_{3 \mathrm{~A}}$ and $\mathrm{H}_{3 \mathrm{~B}}$ : the effect of suits per 100,000 births is statistically significant and negative but so small as to be negligible, while the effect of average payments is not statistically significant. It could be that the state level is too large to capture the effects of proximity to lawsuits. Also, obstetric lawsuits rarely involve issues surrounding the harms caused by induction and none of the allegations in the NPDB were clearly related to induction of labor, so litigation may have little direct effect on induction practices. ${ }^{2}$

\section{DISCUSSION}


This research aimed to assess the deterrent effect of the tort system on adherence to EBM in American maternity care. I used multilevel logistic models to examine the effects of individual- and state-level variables on early-term labor induction without strong medical indications within a specific range of years (1995-2004). Since ACOG guidelines on elective deliveries before 39 weeks have become stricter since 2009 and more hospitals have implemented strict policies on early induction, one expects the effects of tort laws might be similar but weaker after this period.

There are at least two important findings. First, it is clear that individual-level characteristics influence the odds of induction more than state-level factors. The effects of medical characteristics are unsurprising: diabetes, hypertension, high maternal weight gain, and having a previous large infant are all associated with higher odds of induction. However, the odds are also higher for non-Hispanic white women, married women, and women with more education, which are all unrelated to a medical need for early delivery. These are also all markers of privilege in American society, which could support a patient-driven explanation for early-term inductions: non-Hispanic white, educated, and married women may be more likely to ask their care providers to induce labor early and to have their care providers honor their requests than racial-ethnic minorities, unmarried, and less educated women (Kreps 2006; Lazarus 1994; Perloff et al. 2006; Roth and Henley 2012). It is thus possible that maternal request for earlyterm induction could be driving this trend. However, care providers have no duty to offer medically unnecessary or dangerous procedures, and are vulnerable to disciplinary or legal action if they do not follow the professional Standard of Care (SOC). Consequently, patient preferences can only encourage providers to induce labor early when providers are willing to disregard clinical guidelines. 
Secondly, tort laws have clear and significant effects after controlling for state-level fixed effects, socioeconomic indicators, and health insurance environments. The results reveal that early-term induction with weak medical indications is more likely to occur in states with caps on damages that reduce clinicians' tort liability (supporting $\mathrm{H}_{1}$ ). The fact that these effects are significant and substantial even when controlling for the fixed characteristics of states is quite remarkable. In states where tort laws did not change over time, these effects represent the between-state differences between those states that had caps on damages during the entire period of study and those states that had no caps during the whole period. In states that enacted or repealed tort reforms in the 1995-2004 period, these effects represent the odds of risky practices before and after changes in tort laws. States with changes in their laws appear to contribute somewhat more to the effects, suggesting that the implementation of caps has a strong impact on the medical culture within a given state. ${ }^{3}$ The significant effects of caps on damages after controlling for state fixed effects clearly suggest that these caps have an impact on the medical culture within a given state, increasing providers' willingness to engage in risky medical practices.

When it comes to reforming JSL, the results of this analysis suggest that PL encourages more evidence-based practices, which should reduce the number of suits by decreasing the incidence of preventable adverse events (supporting $\mathrm{H}_{2 \mathrm{~B}}$ ) (Currie and MacLeod 2008; Lee et al. 1994). Compared to JSL, PL appears to discourage early-term induction of labor and thus strengthens the deterrent effect of the tort system. Care providers in states with PL may be more cautious because they are liable in proportion to their responsibility for adverse events that occur. However, obstetric malpractice legal activity does not appear to influence the odds of early-term induction, failing to support $\mathrm{H}_{3 \mathrm{~A}}$ and $\mathrm{H}_{3 b}$. This may be unsurprising, since none of the obstetric 
malpractice allegations in the NPDB are clearly connected to induction. As a result, maternity care providers may not connect lawsuits directly to their induction practices.

Revisiting theories of deterrence, the results indicate that the tort system plays an important role in deterring medical practices that carry known risks to patient safety. Previous research has argued that the deterrent effect of medical malpractice liability is weak because most victims of negligent injuries do not pursue legal action or cannot obtain legal representation (Mello and Brennan 2002). However, previous research has focused on the frequency of adverse events that have already occurred, finding alarmingly high rates of negligent error and injury and severe under-compensation of victims (Brennan et al. 1991; Leape et al. 1991; Localio et al. 1991; Mello et al. 2010). Accordingly, analysts' assessments of the efficacy of the tort system for redressing medical errors and compensating victims have found it inadequate because very few negligent medical errors lead to claims and even fewer lead to payments. In contrast, I have analyzed the effects of the tort system on practices that increase the likelihood of negligent injury but do not cause injury in every instance. In this respect, the tort system appears to be an effective deterrent and the findings contribute to the body of evidence against legislation that caps damage awards. Since risky practices like early-term induction of labor do not cause harm in every case, external mechanisms like legal regulation may be necessary to tip the balance in favor of EBM.

\section{$\underline{\text { Limitations and Future Research }}$}

There are some limitations to the data that present opportunities for future research to build on this study. First, while public health and medical research makes extensive use of the Natality Detail files, there are problems with data quality because hospitals must collect the data, submit it to state vital records offices, and then the Natality Branch creates a national data set. 
Data quality thus depends on the training of the hospital staff completing the birth certificate, which is left largely to the states. There is no national standard with follow-up or oversight, leading to inconsistent quality. Lean budgets have also produced lower standards for the timeliness and quality of data since the late 1990s (CDC 2006; Martin et al. 2013). Previous research has found that birth certificates are imperfectly correlated with medical record data, where medical records represent the "gold standard" (DiGiuseppe et al. 2002). Agreement between birth certificates and medical records is "almost perfect" for measures of delivery type, prior obstetrical history, and infant Apgar score. Agreement with medical records is also "substantial" $(k=0.726)$ for several variables including gestational age and prenatal care, but is only moderate for most maternal risk factors and co-morbidities and for several complications of pregnancy, which could lead to misestimates of clinical effects (DiGiuseppe et al. 2002). ${ }^{4}$

Another data limitation is a substantial amount of missing data for variables related to prenatal care and maternal risk factors. Hospitals have a major influence over labor and delivery protocols, and hospitals that provide low-quality birth certificate data are likely to be low-quality in other dimensions. Consequently, I used multiple regression methods to impute missing data for individual-level control variables rather than delete cases with missing values in ways that would select for better-than-average hospitals.

While vital statistics are imperfect, they are the best available population-level indicators for how the legal environment influences patterns of labor induction. Future research might use hospital-level data to further examine effects on elective early-term induction while accounting for variation by physician or by hospital. Hospital-level data might also contain information about insurance, which can influence providers' motivations to induce labor early and may contribute to racial-ethnic, education, and marital status effects (Shi 2001). Given the lack of 
significant effects of litigation, future studies might also obtain finer measures of lawsuit activity at the hospital-, municipal-, or county-level. Greater temporal specificity around lawsuit filings and settlements would be useful for further exploring the effects of the litigation environment on clinicians' behavior.

\section{CONCLUSION}

Despite these limitations, this study provides compelling evidence that tort statutes deter obstetric practices that violate professional recommendations. While 37-38 weeks gestation is technically considered "term," there are well-known risks of neonatal and maternal complications due to early-term delivery. The findings suggest that states that reform their tort statutes to reduce the legal burden on healthcare providers inadvertently encourage high-risk practices in obstetrics, the highest risk specialty in American medicine. Caps on damages undermine the tort system's ability to protect patients from avoidable injury by reducing the pressure on healthcare providers to improve the quality of care (Hyman and Silver 2006). In contrast, tort reforms in the form of PL make clinicians accountable to the extent that they are responsible for injury and encourage improvements in quality (Currie and MacLeod 2008). Thus, this type of reform fits with the deterrence goals of the tort system and is likely to decrease the incidence of medical malpractice (Manzer 1987).

EBM developed to encourage physicians to follow clinical guidelines that are proven to advance patient safety over organizational efficiency (Armstrong 2002; Szymczak and Bosk 2012; Timmermans and Kolker 2004). However, existing sociological analyses of EBM have primarily concerned themselves with questions of who controls the guidelines and how they influence physicians' individual and collective clinical autonomy (Armstrong 2002; 
Mykhalovskiy and Weir 2004; Timmermans and Kolker 2004; Timmermans and Oh 2010).

Alternatively, this study focuses on how adherence to EBM varies according to external regulation through the tort system, which aims to enforce professional standards, deter unethical behavior, and compensate victims for their injuries. 


\section{NOTES}

${ }^{1}$ A likelihood-ratio test is appropriate for comparing multi-level logit models using PROC GLIMMIX in SAS with true maximum likelihood estimates (METHOD=QUAD) (personal communication with Paul Allison, May 25, 2016).

${ }^{2}$ I tested interaction terms for education*married, and for education and marital status by tort laws and FLFP to examine whether education and/or marital status influenced elective labor induction differently across tort and labor market environments. Because interpretation of interaction terms is problematic in logistic models, I also ran linear models to test for robustness (Mood 2010). In both types of model, interactions between education and caps on damages suggest that elective early-term induction is especially common among women with more education when liability risk is lower. Similarly, lower liability risk is associated with more early-term induction for unmarried women. Together, these interactions suggest that lower risk of liability encourages more risky induction practices with educated patients (who may be more inclined to ask for induction for reasons of employment or convenience), and this effect is intensified when those patients are unmarried (possibly signaling stronger labor force constraints compared to their married counterparts). Results are available from the author.

${ }^{3}$ The effects of the tort variables in MLM are partly driven by within-state effects in states that had changes in their tort laws, but they also represent between-state effects after accounting for other fixed characteristics of states with and without caps.

${ }^{4}$ DiGiuseppe et al. (2001) labeled measures with sensitivity and specificity values of $90 \%$ or greater as high. They found no invalid birth certificate data for medical indications for early delivery (pre-eclampsia, eclampsia, polyhydramnios/oligohydramnios, uterine bleeding, premature rupture of membranes, placental abruption, breech presentation, or umbilical cord 
prolapse) or maternal risk measures (diabetes, hypertension, previous infant $>4,000 \mathrm{~g}$ ). There was very little disagreement between medical records and birth certificate data on gestational age: $98.7 \%$ of cases had valid values from both sources and the kappa statistic (which adjusts for agreement that would be observed on the basis of chance) suggested that there was "substantial" agreement $(k=0.726)$. However, measures of pre-eclampsia, eclampsia, polyhydramnios/oligohydramnios, diabetes, hypertension, previous infant $>4,000 \mathrm{~g}$, premature rupture of membranes, placental abruption, placenta previa, breech presentation, and umbilical cord prolapse had low sensitivity ratings, meaning that these conditions were not recorded on birth certificates in some cases where they were present. Consequently, a small number of cases with these conditions may be in the sample despite having medical reasons for early delivery. Similarly, a small number of cases with diabetes, hypertension, or a previous infant $>4000 \mathrm{~g}$ may be incorrectly coded as not having these conditions. However, the incidence of each of these exclusion conditions ranges from $0.2-2 \%$ in both medical records and birth certificates, and the percentage with diabetes or hypertension is $1-4 \%$, so the effects of false negatives on the models are likely to be small. DiGiuseppe et al. (2002) examined data from only one state and thus cannot illuminate the probability of state-level variation in reliability. They also did not examine the reliability of the induction measure, which is the dependent variable in this analysis. 


\section{REFERENCES}

Abbott, Andrew. 1988. The System of Professions. Chicago: The University of Chicago Press.

Abel, Richard L. 1987. “The Real Tort Crisis - Too Few Claims.” Ohio State Law Journal 48: 443-467.

Agency for Healthcare Research and Quality (AHRQ). 2009. "Maternal and neonatal outcomes of elective induction of labor." AHRQ Evidence Report/Technology Assessment No. 176. Rockville, MD: AHRQ.

Allison, Paul. 1999. "Comparing Logit and Probit Coefficients Across Groups.” Sociological Methods \& Research 28(2): 186-208.

Allison, Paul. 2009. Fixed Effects Regression Models. Vol. 160, Sage Publications.

American College of Obstetricians and Gynecologists (ACOG). 2013a. "Definition of Term Pregnancy. ACOG committee opinion no. 579." Obstetrics \& Gynecology 122: 11391140.

American College of Obstetricians and Gynecologists (ACOG). 2013b. "Nonmedically indicated early-term deliveries. ACOG committee opinion no. 561.” Obstetrics \& Gynecology 121(4): 911.

Armstrong, David. 2002. "Clinical Autonomy, Individual and Collective: The Problem of Changing Doctors' Behaviour." Social Science \& Medicine 55(10): 1771-1777.

Asher, Elad, Shay Dvir, Daniel S. Seidman, Sari Greenberg-Dotan, Alon Kedem, Boaz Sheizaf, and Haim Reuveni. 2013. "Defensive Medicine among Obstetricians and Gynecologists in Tertiary Hospitals." PLoS ONE 8(3): e57108.

Avraham, Ronen. 2007. “An Empirical Study of the Impact of Tort Reforms on Medical Malpractice Settlement Payments.” Journal of Legal Studies 36: S183-S229. 
Bates, Elizabeth, Dwight J. Rouse, Merry Lynn Mann, Victoria Chapman, Waldemar A. Carlo, and Alan T.N. Tita. 2010. "Neonatal Outcomes after Demonstrated Fetal Lung Maturity Prior to 39 Weeks of Gestation.” Obstetrics \& Gynecology 116(6): 1288-1295.

Brennan, Troyen A., Lucian L. Leape, Nan M. Laird, Liesi Hebert, A. Russell Localio, Ann G. Lawthers, Joseph P. Newhouse, Paul C. Weiler, and Howard H. Hiatt. 1991. "Incidence of Adverse Events and Negligence in Hospitalized Patients - Results of the Harvard Medical Practice Study I." NEJM 324: 370-376.

Centers for Disease Control (CDC). 2006. "Review of the National Center for Health Statistics Natailty Statistics Program.” Retrieved August 6, 2010 (http://www.cdc.gov/nchs/data/bsc/BSC_NatalityProgramReview.pdf).

Clark, Steven L., Darla D. Miller, Michael A. Belfort, Gary A. Dildy, Donna K. Frye, and Janet A. Meyers. 2009. "Neonatal and maternal outcomes associated with elective term delivery." AJOG 200(2):156.3e1-156.e4.

Currie, Janet, and W. Bentley MacLeod. 2008. "First Do No Harm? Tort Reform and Birth Outcomes." Quarterly Journal of Economics 123(2): 795-830.

DiGiuseppe, David L., David C. Aron, Lorin Ranbom, Dwain L. Harper and Gary E. Rosenthal. 2002. "Reliability of Birth Certificate Data: A Multi-Hospital Comparison to Medical Records Information." Maternal and Child Health Journal 6(3): 169-179.

Dominguez-Bello, Maria G., Elizabeth K. Costello, Monica Contreras, Magda Magris, Gilda Hildalgo, Noah Fierer, and Rob Knight. 2010. "Delivery mode shapes the acquisition and structure of the initial microbiota across multiple body habitats in newborns." Proceedings of the National Academy of Sciences of the United States of America (PNAS) 107(26): 11971-11975. 
Dranove, David, and Yasutora Watanabe. 2009. "Influence and Deterrence: How Obstetricians Respond to Litigation against Themselves and their Colleagues." American Law and Economics Review 12(1): 69-94.

Ehrenthal, Deborah B., Xiaozhang Jiang, and Donna M. Strobino. 2010. "Labor Induction and the Risk of a Cesarean Delivery Among Nulliparous Women at Term." Obstetrics \& Gynecology 116(1): 35-42.

Eisenberg, Theodore, and Martin T. Wells. 2006. “The Significant Association between Punitive and Compensatory Damages in Blockbuster Cases: A Methodological Primer.” Journal of Empirical Legal Studies 3(1): 175-195.

Ene, Mihaela, Elizabeth A. Leighton, Genine L. Blue, and Bethany A. Bell. 2015. "Multilevel Models for Categorical Data using SAS PROC GLIMMIX: The Basics.” Paper 34302015. SAS Institute. University of South Carolina. Retrieved November 20, 2015 (http://support.sas.com/resources/papers/proceedings15/3430-2015.pdf).

Engle, William A., and Michelle A. Kominiarek. 2008. "Late preterm infants, early term infants, and timing of elective deliveries." Clinics in Perinatology 35(2): 325-341.

Frakes, Michael. 2012. "Defensive Medicine and Obstetric Practices.” Journal of Empirical Legal Studies 9(3): 457-481.

Friedson, Eliot. 1970. Profession of Medicine: A Study of the Sociology of Applied Knowledge. New York: Harper and Row Publishers.

Getahun, Darios, Lillian M. Kaminsky, Denise A. Elsasser, Russell S. Kirby, Cande V. Ananth, and Anthony M. Vintzileos. 2007. "Changes in prepregnancy body mass index between pregnancies and risk of primary cesarean delivery." AJOG 197:376.e1-376.e7. 
Glantz, J. Christopher. 2005. "Elective induction vs. spontaneous labor associations and outcomes." Journal of Reproductive Medicine 50: 235-240.

Gregory, Katherine E. 2011. "Microbiome Aspects of Perinatal and Neonatal Health.” Journal of Perinatal and Neonatal Nursing 25(2): 158-164.

Grilli, Roberto, and Jonathan Lomas. 1994. "Evaluating the Relationship between Compliance Rate and the Subject of a Practice Guideline." Medical Care 32(3): 202-213.

Grol, Richard. 2001. "Successes and Failures in the Implementation of Evidence-Based Guidelines for Clinical Practice.” Medical Care 39(8), S2: II-46-II-54.

Hyman, David A., and Charles Silver. 2006. "Medical Malpractice Litigation and Tort Reform: It's the Incentives, Stupid." Vanderbilt Law Review 59(4): 1085-1136.

Institute of Medicine. 2009. Weight Gain During Pregnancy: Reexamining the Guidelines. Kathleen M. Rasmussen and Ann L. Yaktine (Ed). Washington, DC: National Academies Press.

James, John T. 2013. “A New, Evidence-based Estimate of Patient Harms Associated with Hospital Care.” Journal of Patient Safety 9(3): 122-128.

Kreps, Gary L. 2006. “Communication and Racial Inequities in Health Care.” American Behavioral Scientist 49(6): 760-774.

Lazarus, Ellen S. 1994. "What do women want? Issues of choice, control, and class in pregnancy and childbirth." Medical Anthropology Quarterly 8(1): 25-46.

Leape, Lucian L., Troyen A. Brennan, Nan Laird, Ann G. Lawthers, A. Russell Localio, Benjamin A. Barnes, Liesi Hebert, Joseph P. Newhouse, Paul C. Weiler, and Howard Hiatt. 1991. "The Nature of Adverse Events in Hospitalized Patients - Results of the Harvard Medical Malpractice Study II.” NEJM 324: 377-384. 
Lee, Han-Duck, Mark J. Browne, and Joan T. Schmit. 1994. "How does Joint and Several Tort Reform affect the Rate of Tort Filings? Evidence from the State Courts." The Journal of Risk and Insurance 61(2): 295-316.

Leigh, J. Paul, Richard L. Kravitz, Mike Schembri, Steven J. Samuels, and Shanaz Mobley. 2002. "Physician Career Satisfaction Across Specialties." Archives of Internal Medicine 162(14): 1577-1584.

Localio, A. Russell, Ann G. Lawthers, Troyen A. Brennan, Nan M. Laird, Liesi E. Hebert, Lynn M. Peterson, Joseph P. Newhouse, Paul C. Weiler, and Howard H. Hiatt. 1991. "Relation between Malpractice Claims and Adverse Events Due to Negligence.” NEJM 325(4): 245-251.

Lofquist, William S. 2002. "Closing the Courthouse Door: Constructing Undeservingness in the Tort and Habeas Corpus Reform Movements.” Sociological Spectrum 22: 191-223.

Lyon, Larry, Bradley J.B. Toben, James M. Underwood, William D. Underwood, and James Wren. 2007. "Straight from the Horse's Mouth: Judicial Observations of Jury Behavior and the Need for Tort Reform.” Baylor Law Review 59(2): 419-434.

MacCoun, Robert J. 1996. “Differential Treatment of Corporate Defendants by Juries: An Examination of the 'Deep Pockets' Hypothesis.” Law \& Society Review 30(1): 121-162.

Manzer, Nancy L. 1987. “1986 Tort Reform Legislation: A Systematic Evaluation of Caps on Damages and Limitations on Joint and Several Liability." Cornell Law Review 73: 628652.

Martin, Joyce A., Elizabeth C. Wilson, Michelle J.K. Osterman, Elizabeth W. Saadi, Shae R. Sutton, and Brady E. Hamilton. 2013. “Assessing the Quality of Medical and Health Data 
from the 2003 Birth Certificate Revision: Results from Two States.” National vital statistics reports 62(2). Hyattsville, MD: National Center for Health Statistics.

Mello, Michelle M., and Troyen A. Brennan. 2002. "Deterrence of Medical Errors: Theory and Evidence for Malpractice Reform.” Texas Law Review 80(3): 1595-1637.

Mello, Michelle M., Amitabh Chandra, Atul A. Gawande, and David M. Studdert. 2010. "National Costs of the Medical Liability System." Health Affairs 29(9): 1569-1577.

Metzler, Ian S., and John G. Meara. 2012. "Medical liability reform: Evidence for legislative and alternative approaches." Bulletin of the American College of Surgeons. Retrieved April 3, 2015 (http://bulletin.facs.org/2012/01/medical-liability/\#).

Mood, Carina. 2010. "Logistic Regression: Why We Cannot Do What We Think We Can Do, and What We Can Do About It.” European Sociological Review 26(1): 67-82.

Morrison, John J., Janet M. Rennie, and Peter J. Milton. 1995. "Neonatal respiratory morbidity and mode of delivery at term: influencing of timing of elective cesarean delivery." BJOG 102(2): 101-106.

Murthy, Karna, William A. Grobman, Todd A. Lee, and Jane L. Holl. 2011. "Trends in Induction of Labor at Early-term Gestation." AJOG 204:435.e1-6.

Mykhalovskiy, Eric, and Lorna Weir. 2004. “The Problem of Evidence-Based Medicine: Directions for Social Science.” Social Science \& Medicine 59(5): 1059-1069.

National Center for Health Statistics. 2008. Natality Detail Files, 1995-2004. [Computer files.] Hyattsville, MD: U.S. Dept. of Health and Human Services [producer]. Ann Arbor, MI: Inter-university Consortium for Political and Social Research [distributor]. 
Perloff, Richard M., Bette Bonder, George B. Ray, Eileen Berlin Ray, and Laura A. Siminoff. 2006. "Doctor-Patient Communication, Cultural Competence, and Minority Health: Theoretical and Empirical Perspectives.” American Behavioral Scientist, 49(6): 835-852.

Raudenbush, Stephen W. and Anthony S. Bryk. 2002. Hierarchical Linear Models: Applications and Data Analysis Methods. Second Edition. Thousand Oaks, California: Sage Publications.

Rayburn, William F., and J. Zhang. 2002. "Rising rates of labor induction: Present concerns and future strategies." Obstetrics \& Gynecology 100(1): 164.

Rosenberg, Terry J., Samantha Garbers, Wendy Chavkin, and Mary Ann Chiasson. 2003. "Prepregnancy weight and adverse perinatal outcomes in an ethnically diverse population." Obstetrics \& Gynecology 102: 1022-1027.

Roth, Louise Marie, and Megan M. Henley. 2012. "Unequal Motherhood: Inequality in Cesarean Sections in the United States." Social Problems 59(2): 207-227.

Shi, Leiyu. 2001. "The convergence of vulnerable characteristics and health insurance in the U.S.” Social Science \& Medicine 53: 519-529.

Signore, Caroline. 2010. "No Time for Complacency: Labor Inductions, Cesarean Deliveries, and the Definition of 'Term.'” Obstetrics \& Gynecology 116(1): 4-6.

Simpson, Kathleen Rice. 2010. "Reconsideration of the Costs of Convenience: Quality, Operational, and Fiscal Strategies to Minimize Elective Labor Induction.” Journal of Perinatal \& Neonatal Nursing 24(1): 43-52.

Simpson, Kathleen Rice, and Kathleen E. Thorman. 2005. “Obstetric 'Conveniences': Elective Induction of Labor, Cesarean Birth on Demand, and Other Potentially Unnecessary Interventions." Journal of Perinatal \& Neonatal Nursing 19(2): 134-144. 
Spong, Catherine Y., Brian M. Mercer, Mary D’Alton, Sarah Kilpatrick, Sean Blackwell, and George Saade. 2011. "Timing of Indicated Late-Preterm and Early-Term Birth." Obstetrics \& Gynecology 118(2 Part 1): 323-333.

Studdert, David M., Michelle M. Mello, William M. Sage, Catherine M. DesRoches, Jordon Peugh, Kinga Zapert, and Troyen A. Brennan. 2005. "Defensive Medicine Among HighRisk Specialist Physicians in a Volatile Malpractice Environment.” JAMA 293(21): 26092617.

Szymczak, Julia, and Charles L. Bosk. 2012. “Training for Efficiency: Work, Time, and Systems-Based Practice in Medical Residency." Journal of Health and Social Behavior 53(3): 344-358.

Timmermans, Stefan, and Emily S. Kolker. 2004. "Evidence-Based Medicine and the Reconfiguration of Medical Knowledge.” Journal of Health and Social Behavior 45: 177-193.

Timmermans, Stefan, and Hyeyoung Oh. 2010. "The Continued Social Transformation of the Medical Profession.” Journal of Health and Social Behavior 51(S): S94-S106.

U.S. Department of Health and Human Services. 2015. National Practitioner Data Bank Public Use Data File (NPDB) [Computer file]. Health Resources and Services Administration. Rockville, MD: U.S. Department of Health and Human Services.

Vidmar, Neil. 1997. Medical malpractice and the American jury: confronting the myths about jury incompetence, deep pockets, and outrageous damage awards. Ann Arbor MI: University of Michigan Press.

Vrouenraets, Francis P., Frans J. Roumen, Cary J. Dehing, Eline S. A. van den Akker, Maureen J. B. Aarts, and Esther J. Scheve. 2005. "Bishop Score and Risk of Cesarean Delivery 
after Induction of Labor in Nulliparous Women.” Obstetrics \& Gynecology 105(4): 690697.

Wing, Deborah A. 2000. "Elective induction of labor in the USA." Current Opinion in Obstetrics and Gynecology 12: 457-462.

Yang, Y. Tony, Michelle M. Mello, S.V. Subramanian, and David M. Studdert. 2009. "Relationship between Malpractice Litigation Pressure and Rates of Cesarean Section and Vaginal Birth after Cesarean Section.” Medical Care 47(2): 234-242. 
Table 1: Descriptions and Descriptive Statistics for State-Level Controls

\begin{tabular}{|c|c|c|c|}
\hline Variable & Metric & Mean (SD) & Source \\
\hline $\begin{array}{l}\text { Per capita } \\
\text { income }(\mathrm{PCI})\end{array}$ & In $\$ 1000$ s of 2004 dollars & $31.48(4.18)$ & $\begin{array}{c}\text { U.S. Bureau of } \\
\text { Economic Analysis }\end{array}$ \\
\hline$\%$ Poverty & $\%$ living below federal poverty line & $12.15(3.47)$ & U.S. Census Bureau \\
\hline FLFP & $\begin{array}{l}\text { Female labor force participation rate } \\
(\%)\end{array}$ & $62.11(22.42)$ & $\begin{array}{l}\text { U.S. Bureau of } \\
\text { Labor Statistics }\end{array}$ \\
\hline$\% \mathrm{HMO}$ & $\begin{array}{l}\% \text { enrolled in Health Maintenance } \\
\text { Organizations }\end{array}$ & $20.25(12.79)$ & \multirow{3}{*}{$\begin{array}{c}\text { U.S. Census Bureau, } \\
\text { Current Population } \\
\text { Surveys }\end{array}$} \\
\hline$\%$ Uninsured & $\%$ without health insurance & $14.05(3.92)$ & \\
\hline$\%$ Medicaid & $\%$ on Medicaid & $11.17(3.57)$ & \\
\hline Beds & Hospital beds per 1,000 population & $3.25(1.08)$ & $\begin{array}{l}\text { U.S. Dept of Health } \\
\text { and Human Services }\end{array}$ \\
\hline Suit rate & $\begin{array}{l}\text { \# OB malpractice suits/100,000 births } \\
\text { previous year }\end{array}$ & $28.0(32.96)$ & \multirow{2}{*}{$\begin{array}{l}\text { National Practitioner } \\
\text { Data Bank, Public } \\
\text { Use Data File }\end{array}$} \\
\hline Average award & $\begin{array}{l}\text { Payment per OB malpractice suit } \\
\text { previous year in } 2004 \text { dollars }\end{array}$ & $\begin{array}{l}\$ 435,434.88 \\
(278,702.16)\end{array}$ & \\
\hline $\mathrm{N}$ & State-years over 10 years & 510 & \\
\hline
\end{tabular}

Table 2: Descriptions and Descriptive Statistics for State-Level Tort Variables

\begin{tabular}{|c|c|c|c|}
\hline Variable & Metric & $\%$ & Source \\
\hline $\begin{array}{l}\text { Cap on punitive } \\
\text { damages }\end{array}$ & Cap on punitive damages only & $21.9 \%$ & $\begin{array}{c}\text { American Tort } \\
\text { Reform Association }\end{array}$ \\
\hline Cap NE >500k & $\begin{array}{l}\text { Non-economic damages cap above } \\
\$ 500,000\end{array}$ & $13.8 \%$ & \multirow[t]{3}{*}{$\begin{array}{l}\text { Senate Judiciary } \\
\text { Committee }\end{array}$} \\
\hline Cap NE 500 & $\begin{array}{l}\text { Non-economic damages cap of } \\
\$ 250,001-\$ 500,000\end{array}$ & $15.5 \%$ & \\
\hline Cap NE 250 & Non-economic damages cap $<=\$ 250,000$ & $9.0 \%$ & \\
\hline JSL reform & $\begin{array}{l}0=\mathrm{JSL} ; 1=\text { proportionate liability or } \\
\text { defendant must be responsible for }>20 \% \\
\text { of harm }\end{array}$ & $57.3 \%$ & $\frac{\underline{\text { http://www.econ.col }}}{\underline{\text { umbia.edu/public d }}}$ \\
\hline $\mathrm{N}$ & State-months over 10 years & 6,120 & \\
\hline
\end{tabular}


Table 3: Descriptive Statistics for Early-Term Births (37-38 weeks) to Mothers without a Prior Cesarean, 1995-2004

\begin{tabular}{|c|c|c|}
\hline VARIABLE & SPONTANEOUS & INDUCED \\
\hline & MEAN (SD) OR PERCENT & MEAN (SD) OR PERCENT \\
\hline Year $1=1995$ to $10=2004$ & $\begin{array}{c}5.53 \\
(2.82)\end{array}$ & $\begin{array}{c}6.00^{* * *} \\
(2.73)\end{array}$ \\
\hline \multicolumn{3}{|l|}{ Demographic Characteristics } \\
\hline Maternal age (in years) & $\begin{array}{l}26.85 \\
(6.20)\end{array}$ & $\begin{array}{l}27.54 * * * \\
(6.06)\end{array}$ \\
\hline Education (in years) & $\begin{array}{l}12.69 \\
(2.83)\end{array}$ & $\begin{array}{c}13.22 * * * \\
(2.48)\end{array}$ \\
\hline Hispanic/Latina & $22.3 \%$ & $13.0 \% * * *$ \\
\hline White (non-Hispanic) (ref) & $75.9 \%$ & $83.1 \% * * *$ \\
\hline Black (non-Hispanic) & $17.2 \%$ & $12.7 \% * * *$ \\
\hline Native American & $1.0 \%$ & $0.9 \% *$ \\
\hline Asian & $5.9 \%$ & $3.2 \% * * *$ \\
\hline Married & $64.9 \%$ & $71.9 \% * * *$ \\
\hline \multicolumn{3}{|l|}{ Pregnancy Characteristics } \\
\hline Parity (\# of births) & $\begin{array}{c}2.05 \\
(1.21)\end{array}$ & $\begin{array}{c}2.10 * * * \\
(1.18)\end{array}$ \\
\hline $\begin{array}{l}\text { APNCU }(1=\text { inadequate, to } \\
4=\text { adequate }+)\end{array}$ & $\begin{array}{c}3.09 \\
(0.95)\end{array}$ & $\begin{array}{c}3.24 * * * \\
(0.85)\end{array}$ \\
\hline Weight gain (in lbs) & $\begin{array}{c}29.71 \\
(11.31)\end{array}$ & $\begin{array}{c}30.46^{* * *} \\
(12.83)\end{array}$ \\
\hline Weight gain $>45 \mathrm{lbs}$ & $9.1 \%$ & $12.5 \% * * *$ \\
\hline Previous infant $>4 \mathrm{~kg}$ & $0.6 \%$ & $1.8 \% * * *$ \\
\hline Diabetes & $2.4 \%$ & $5.8 \% * * *$ \\
\hline Hypertension & $0.5 \%$ & $2.4 \% * * *$ \\
\hline $\mathbf{N}$ & 545,487 & 120,004 \\
\hline Percent & $82.0 \%$ & $18.0 \%$ \\
\hline
\end{tabular}

Source: Natality Detail Files 1995-2004

2-tailed t-test for difference: $\quad * \mathrm{p}<0.05$

$* * \mathrm{p}<0.01 \quad * * * \mathrm{p}<.0001$ 
Table 4: Multilevel Logit Models of Labor Induction in Early-Term Births (37-38 weeks) to Mothers without a Prior Cesarean, 1995-2004

\begin{tabular}{|c|c|c|c|}
\hline & Model 1 & Model 2 & Model 3 \\
\hline Fixed Effects & OR (SE) & OR (SE) & OR (SE) \\
\hline \multicolumn{4}{|c|}{ Birth-Level Fixed Effects } \\
\hline Intercept $^{\mathrm{a}}$ & $\begin{array}{c}-1.95 * * * \\
(0.04)\end{array}$ & $\begin{array}{c}-1.36 * * * \\
(0.09)\end{array}$ & $\begin{array}{c}-1.43 * * * \\
(0.09)\end{array}$ \\
\hline Year & $\begin{array}{l}1.07 * * * \\
(0.001)\end{array}$ & $\begin{array}{c}1.08 * * * \\
(0.002)\end{array}$ & $\begin{array}{l}1.07 * * * \\
(0.002)\end{array}$ \\
\hline Maternal age & $\begin{array}{c}0.996 * * * \\
(0.001)\end{array}$ & $\begin{array}{c}0.996 * * * \\
(0.001)\end{array}$ & $\begin{array}{c}0.996^{* * * *} \\
(0.001)\end{array}$ \\
\hline Education & $\begin{array}{l}1.04 * * * \\
(0.002)\end{array}$ & $\begin{array}{l}1.04 * * * \\
(0.002)\end{array}$ & $\begin{array}{c}1.04 * * * \\
(0.002)\end{array}$ \\
\hline Hispanic & $\begin{array}{c}0.58 * * * \\
(0.01)\end{array}$ & $\begin{array}{c}0.58 * * * \\
(0.01)\end{array}$ & $\begin{array}{c}0.58 * * * \\
(0.01)\end{array}$ \\
\hline Black & $\begin{array}{c}0.62 * * * \\
(0.01)\end{array}$ & $\begin{array}{c}0.62 * * * \\
(0.01)\end{array}$ & $\begin{array}{c}0.62 * * * \\
(0.01)\end{array}$ \\
\hline Native American & $\begin{array}{c}0.77 * * * \\
(0.03)\end{array}$ & $\begin{array}{c}0.76^{* * * *} \\
(0.03)\end{array}$ & $\begin{array}{c}0.77 * * * \\
(0.03)\end{array}$ \\
\hline Asian & $\begin{array}{c}0.51 * * * \\
(0.02)\end{array}$ & $\begin{array}{c}0.51 * * * \\
(0.02)\end{array}$ & $\begin{array}{c}0.51 * * * \\
(0.02)\end{array}$ \\
\hline Married & $\begin{array}{c}1.09 * * * \\
(0.01)\end{array}$ & $\begin{array}{c}1.08 * * * \\
(0.01)\end{array}$ & $\begin{array}{c}1.08^{* * *} \\
(0.01)\end{array}$ \\
\hline Parity & $\begin{array}{c}1.07 * * * \\
(0.003)\end{array}$ & $\begin{array}{c}1.06 * * * \\
(0.003)\end{array}$ & $\begin{array}{c}1.06 * * * \\
(0.003)\end{array}$ \\
\hline APNCU & $\begin{array}{l}1.14 * * * \\
(0.004)\end{array}$ & $\begin{array}{c}1.14 * * * \\
(0.004)\end{array}$ & $\begin{array}{l}1.14 * * * \\
(0.004)\end{array}$ \\
\hline Weight gain $>45 \mathrm{lbs}$ & $\begin{array}{c}1.26 * * * \\
(0.01)\end{array}$ & $\begin{array}{c}1.26^{* * * *} \\
(0.01)\end{array}$ & $\begin{array}{c}1.26^{* * * *} \\
(0.01)\end{array}$ \\
\hline Previous infant $>4 \mathrm{~kg}$ & $\begin{array}{c}2.48 * * * \\
(0.03)\end{array}$ & $\begin{array}{c}2.48 * * * \\
(0.03)\end{array}$ & $\begin{array}{c}2.47 * * * \\
(0.03)\end{array}$ \\
\hline Diabetes & $\begin{array}{c}2.29 * * * \\
(0.02)\end{array}$ & $\begin{array}{c}2.28 * * * \\
(0.02)\end{array}$ & $\begin{array}{c}2.28^{* * * *} \\
(0.02)\end{array}$ \\
\hline Hypertension & $\begin{array}{c}3.79 * * * \\
(0.03)\end{array}$ & $\begin{array}{c}3.78 * * * \\
(0.03)\end{array}$ & $\begin{array}{c}3.79 * * * \\
(0.03)\end{array}$ \\
\hline \multicolumn{4}{|c|}{ State-Level Fixed Effects } \\
\hline PCI & & $\begin{array}{c}0.99 * * * \\
(0.002)\end{array}$ & $\begin{array}{c}0.99 * * * \\
(0.002)\end{array}$ \\
\hline$\%$ Poverty & & $\begin{array}{c}1.01 \\
(0.003)\end{array}$ & $\begin{array}{c}1.01 \\
(0.003)\end{array}$ \\
\hline FLFP & & $\begin{array}{c}1.00 \\
(0.000)\end{array}$ & $\begin{array}{c}1.00 \\
(0.000)\end{array}$ \\
\hline$\% \mathrm{HMO}$ & & $\begin{array}{c}1.003 * * \\
(0.001)\end{array}$ & $\begin{array}{l}1.003 * * \\
(0.001)\end{array}$ \\
\hline$\%$ Uninsured & & $\begin{array}{c}1.003 \\
(0.003)\end{array}$ & $\begin{array}{c}1.001 \\
(0.003)\end{array}$ \\
\hline$\%$ Medicaid & & $\begin{array}{c}0.99 * * * \\
(0.003)\end{array}$ & $\begin{array}{c}0.99 * * * \\
(0.003)\end{array}$ \\
\hline Beds & & $\begin{array}{c}0.97 * * * \\
(0.01)\end{array}$ & $\begin{array}{c}0.97 * * \\
(0.01)\end{array}$ \\
\hline
\end{tabular}




\begin{tabular}{|c|c|c|c|}
\hline Cap on punitive damages (1=yes) & & & $\begin{array}{c}1.15^{* * *} \\
(0.02)\end{array}$ \\
\hline $\begin{array}{l}\text { Cap NE }>500 \text { ( } 1=\text { cap of }>\$ 500,000 \\
\text { on non-economic damages })\end{array}$ & & & $\begin{array}{c}1.33^{* * * *} \\
(0.03)\end{array}$ \\
\hline $\begin{array}{l}\text { Cap NE } 500 \text { ( } 1=\text { cap of } \$ 250,001- \\
500,000 \text { on non-economic damages) }\end{array}$ & & & $\begin{array}{c}1.30^{* * * *} \\
(0.03)\end{array}$ \\
\hline $\begin{array}{l}\text { Cap NE } 250(1=\text { cap of }<=\$ 250,000 \\
\text { on non-economic damages })\end{array}$ & & & $\begin{array}{c}1.39 * * * \\
(0.03)\end{array}$ \\
\hline JSL reform & & & $\begin{array}{c}0.78^{* * * *} \\
(0.03)\end{array}$ \\
\hline Suit rate & & & $\begin{array}{l}0.999 * * * \\
(0.000)\end{array}$ \\
\hline Average award & & & $\begin{array}{c}1.00 \\
(0.000)\end{array}$ \\
\hline \multicolumn{4}{|l|}{ Random Effects } \\
\hline State Variance Component & $\begin{array}{c}0.08 * * * \\
(0.02)\end{array}$ & $\begin{array}{c}0.09 * * * \\
(0.02)\end{array}$ & $\begin{array}{c}0.08 * * * \\
(0.01)\end{array}$ \\
\hline Births (N) & 665,491 & 665,491 & 665,491 \\
\hline States & 51 & 51 & 51 \\
\hline Max births/state & 89,410 & 89,410 & 89,410 \\
\hline$-2 \mathrm{LL}$ & $596,440.6^{* * *}$ & $596,361.6^{* * *}$ & $596,145.4 * * *$ \\
\hline
\end{tabular}

Source: Natality Detail Files 1995-2004

Note: $* \mathrm{p}<0.05 \quad * * \mathrm{p}<0.01 \quad * * * \mathrm{p}<.0001$

${ }^{\mathrm{a}}$ Intercepts are coefficients, not odds ratios. 